\title{
Analysis of Data Acquisition Accuracy with UAV
}

\author{
Balázsik, V., ${ }^{1^{*}}$ Tóth, Z. ${ }^{1}$ and Abdurahmanov, I. ${ }^{2}$ \\ ${ }^{1}$ Institute of Geoinformatics, Obuda University, Pirosalma str., 1-3, 8000, Székesfehérvár, Hungary \\ E-mail: balazsik.valeria@uni-obuda.hu, toth.zoltan@uni-obuda.hu \\ ${ }^{3}$ Faculty of Land Management, Tashkent Institute of Irrigation and Agricultural Mechanization Engineers, \\ Kari Niyaziy str., 39, 100000, Tashkent, Uzbekistan, E-mail: ilhom.isakovich@tiiame.uz \\ * Corresponding author
}

\begin{abstract}
Due to the increasingly advanced digital devices, high resolution cameras and utility of fast processing, Unmanned Aerial Vehicles (UAV) have become a prominent feature of the various remote sensing procedures. Because the benefits of the technology may justify the use of data in topographic mapping, cadastral mapping or even engineering geodesy, we have conducted studies to determine the accuracy that can be achieved using UAV as an integrated data acquisition tool. First, we developed a test field in rural area for investigations. The results of the test flights conducted there were determined that what conditions influence the accuracy of the survey.
\end{abstract}

\section{Introduction}

By processing images created with UAV technology, we can produce a variety of products, including point cloud, 3-dimensional surface model or orthophoto mosaic. By further processing, we can define point-to-point 3-dimensional coordinates or create vector maps. Processing products can be utilized in Geographic Information Systems (GIS) depending on the accuracy achieved. As orthophotos show actual land cover, they can be used properly to update the planimetric content of topographic maps and can also meet the precision requirements. For smaller areas, the elevation content changes of topographic map can also be updated based on point cloud or digital surface model. Such changes can be the result of earthwork in the construction of motorways, open-cast mining, etc.

In most countries, cadastre is used to define the dimensions and location of land parcels and the objects on it according to the legal regulations of the respective country. Cadastral maps are the graphical documentation of the ownership; all parcels have registered address and unique identifier, without which the sale and purchase of a real estate cannot take place. The accurate and up-to-date cadastral maps are important and basic components of GIS. Due to the low fly altitude a camera mounted on a UAV enables high-resolution imagery, but does the process result in sufficiently accurate data suitable for cadastral mapping? In most cases these measuring systems are equipped with low-cost amateur digital cameras. As the optical distortion of amateur cameras is larger than the distortion of

professional photogrammetric cameras, demanding the examination of how camera calibration influences the geometric accuracy of UAV surveys. In the investigations, in each case, we took into account whether the survey was conducted with a calibrated camera, but not considering the method of the calibration procedure. We analysed of the effect of the UAV flight altitude on the accuracy of point coordinates. Surveys were conducted with different types of UAVs (fixed wing or rotor system), the cameras' resolution was different, and external orientation was solved in various ways, either directly, using GNSS or using Ground Control Points (GCP). Each case of the study was different in terms of tools and methods, but in the present analysis all have been considered as an integrated measurement system, and the accuracy of such an integrated system was determined.

\section{Establishment of a Test Field}

Although complex calibration test tracks have been developed worldwide (Honkavaara et al., 2013, Tommaselli et al., 2014, Hamid and Ahmad, 2014 and Tommaselli et al., 2016), no such developments have been made in Hungary before. The following section describes the construction of a test field for the purpose of qualifying the accuracy of the UAV geodetic survey and the results of the first test flights. The developed test field is located in a rural hilly area and is approximately $200 \mathrm{~m} \times 200 \mathrm{~m}$ wide. On the field 7 x $7=49$ point marks have been placed roughly in raster arrangement, approximately north oriented. The test area has poor vegetation and 
is covered with low grass; the maximum height difference is approximately $20 \mathrm{~m}$. The arrangement of the points in the test field is shown in Figure 1.

$50 \times 50 \mathrm{~cm}$ black and white boards made of plastic were used for point marking (Figure 2). The relatively large size of the points is due to the homogeneous surface coverage of the area; the absence of surface features, according to past experience, may cause problems with automatic matching of images. Although the points were marked temporarily, two points were lost during its approximately one year of existence.

\subsection{Determination of Test Field Points}

UAVs for geodetic data acquisition have been shown to be capable of capturing 2-3 cm resolution and, due to the large number of images and multiple overlaps, they can achieve an accuracy of a few $\mathrm{cm}$ after processing. As a result, the test field points are expected to form a spatially (horizontally and vertically as well) homogeneous network with mean error of less than $\pm 1 \mathrm{~cm}$. In the case of the test field, the survey has been done purely by total station and the coordinates were determined by adjusting as an independent network, and finally it has been inserted into the national projection system of Hungary (EOV).

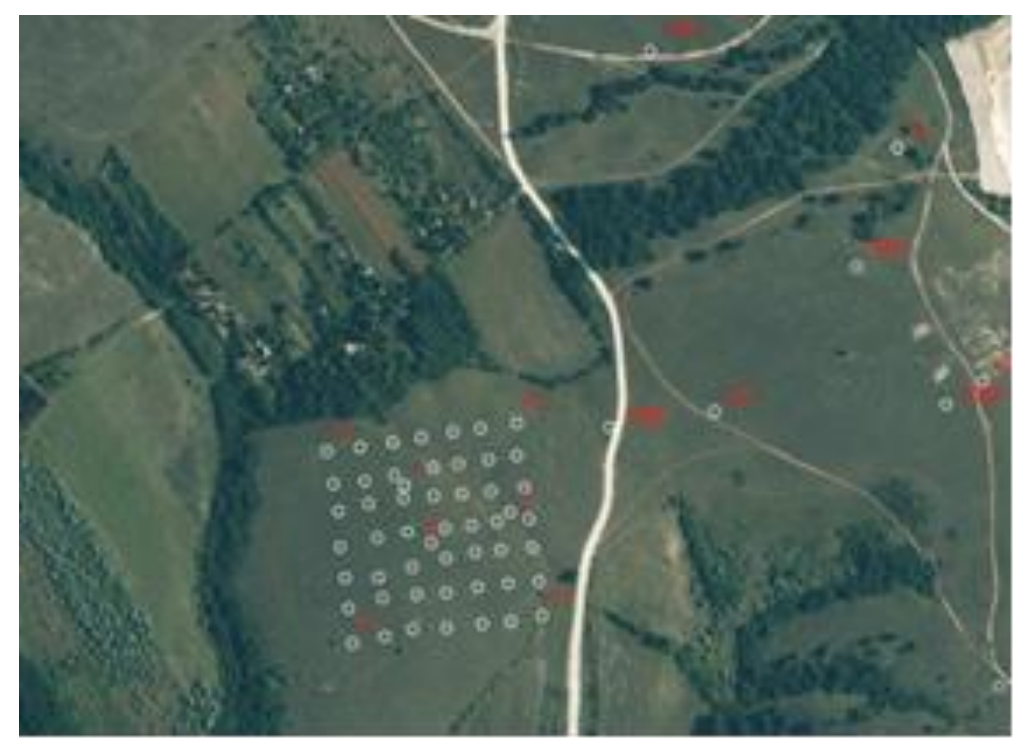

Figure 1: The arrangement of the points of test field (Balázsik et al., 2016)

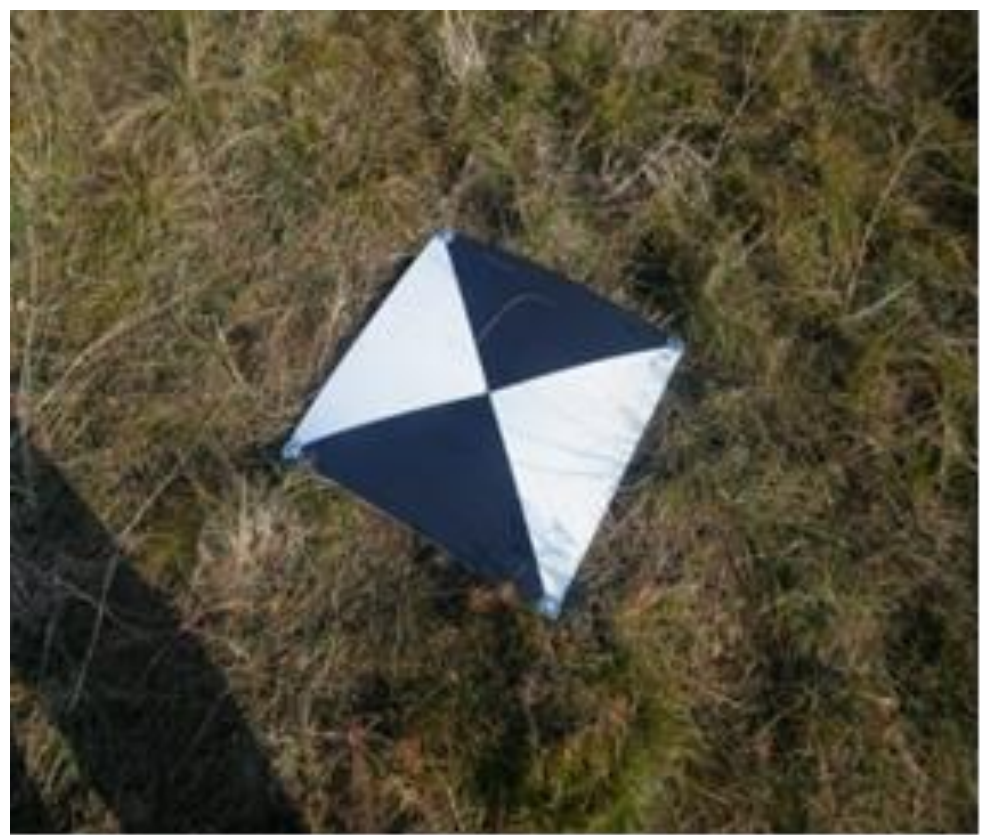

Figure 2: The point mark on the test field 


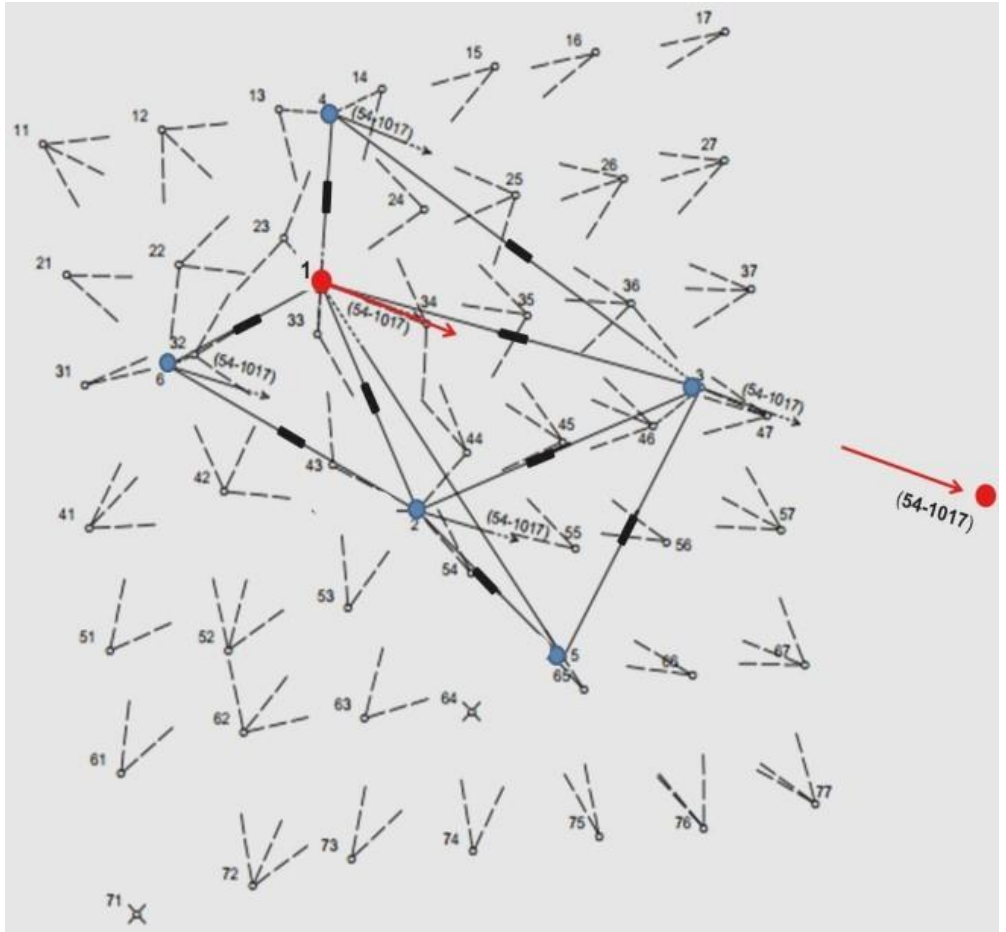

Figure 3: Scheme for determining points in the test field (Balázsik at al., 2016)

Table 1: Some technical parameters of the devices and surveying involved in the study

\begin{tabular}{|c|c|c|c|c|c|}
\hline $\begin{array}{c}\text { Uav } \\
\text { Number }\end{array}$ & Type & $\begin{array}{c}\text { Camera } \\
\text { Resolution }\end{array}$ & $\begin{array}{c}\text { Calib-Rated } \\
\text { Yes/No }\end{array}$ & $\begin{array}{c}\text { Flying } \\
\text { Altitude }\end{array}$ & $\begin{array}{c}\text { Number of } \\
\text { Images }\end{array}$ \\
\hline $\mathbf{1}$ & fixed-wing & $16 \mathrm{Mp}$ & Y & 75 & 300 \\
\hline $\mathbf{2}$ & multi- rotor & $20 \mathrm{Mp}$ & Y & 80 & 250 \\
\hline $\mathbf{3}$ & multi-rotor & $12 \mathrm{Mp}$ & Y & 116 & 16 \\
\hline $\mathbf{4}$ & fixed-wing & $16 \mathrm{Mp}$ & Y & 120 & 300 \\
\hline $\mathbf{5}$ & fixed-wing & $16 \mathrm{Mp}$ & N & 90 & 170 \\
\hline
\end{tabular}

Each point was determined using at least two, but in most cases three directions (Figure 3). The average reliability of the resulting coordinates was $\pm 0.4 \mathrm{~cm}$ horizontally, $\pm 0.7 \mathrm{~cm}$ vertically, with maxima of $\pm 0.5 \mathrm{~cm}$ and $\pm 1.1 \mathrm{~cm}$, respectively for horizontal and vertical directions.

\subsection{Results of Calibrations}

With 5 different types of UAVs, there were 6 test flights performed over the test field. Table 1 shows some of the key features of each flight. Table 2 summarizes the average statistics for each survey: mean coordinate differences in $\mathrm{X}, \mathrm{Y}$, and $\mathrm{Z}$, horizontal (2D), and spatial (3D) mean errors. While no blunders were found in the horizontal direction, there were occasional differences in height coordinates of $\pm 10 \mathrm{~cm}$; these were interpreted as vertical blunder error, and the number of occurrences is shown in the last column of the table.
Regarding the horizontal coordinate differences, we found cases when the point errors are in the same or almost the same direction as the flight and approximately in the direction of the reference system $\mathrm{Y}$ axis. This may be related to the direction of flight or to GNSS reference frame errors (Figure $4)$. The greater horizontal errors were most frequent at the edges of the test area, which may be due to the fact that while the number of overlaps inside the area is $8-10$, at the edges it is only 1-2 (Figure 5). Horizontal errors are represented by circles with radius proportional to the error. For scaling, the size of the circle corresponding to $1 \mathrm{~cm}$ horizontal error is shown in the lower left corner of the figure. The vertical errors did not show a direct correlation with the terrain characteristics, although it is true that the topography of test field is simple, there are no sharp surface changes (Figure 6). In order to investigate the effect of the topography and further flight characteristics on the survey error, we have begun to 
establish a more complex test area, which, besides $\mathrm{UAVs}$, is capable of investigating various mobile data acquisition devices (MMS) and investigating possible sources of errors based on more cases (Figure 7).

Table 2: Statistics for comparing geodetic coordinates

\begin{tabular}{|c|c|c|c|c|c|c|}
\hline flight no. & $\begin{array}{c}\mathbf{Y}- \\
\text { direction } \\
\text { error [cm] }\end{array}$ & $\begin{array}{c}\mathbf{X}- \\
\text { direction } \\
\text { error [cm] }\end{array}$ & $\begin{array}{c}\text { 2D point } \\
\text { error [cm] }\end{array}$ & $\begin{array}{c}\text { Z- } \\
\text { direction } \\
\text { error [cm] }\end{array}$ & $\begin{array}{c}\text { 3D point } \\
\text { error [cm] }\end{array}$ & $\begin{array}{c}\text { number of vertical } \\
\text { blunders }\end{array}$ \\
\hline $\mathbf{1}$ & 3,9 & 1,4 & 4,3 & 1,2 & 4,6 & 0 \\
\hline $\mathbf{2}$ & 1,1 & 1,0 & 1,7 & 2,2 & 2,9 & 0 \\
\hline $\mathbf{3 / 1}$ 1.flight & 1,5 & 2,3 & 3,0 & 4,1 & 4,3 & 1 \\
\hline $\mathbf{3 / 2} \mathbf{2 . f l i g h t}$ & 1,2 & 1,3 & 2,0 & 3,2 & 3,2 & 0 \\
\hline $\mathbf{4}$ & 1,5 & 1,0 & 1,9 & 2,9 & 4,2 & 0 \\
\hline $\mathbf{5}$ & 4,3 & 1,6 & 4,8 & 5,9 & 8,0 & 4 \\
\hline
\end{tabular}
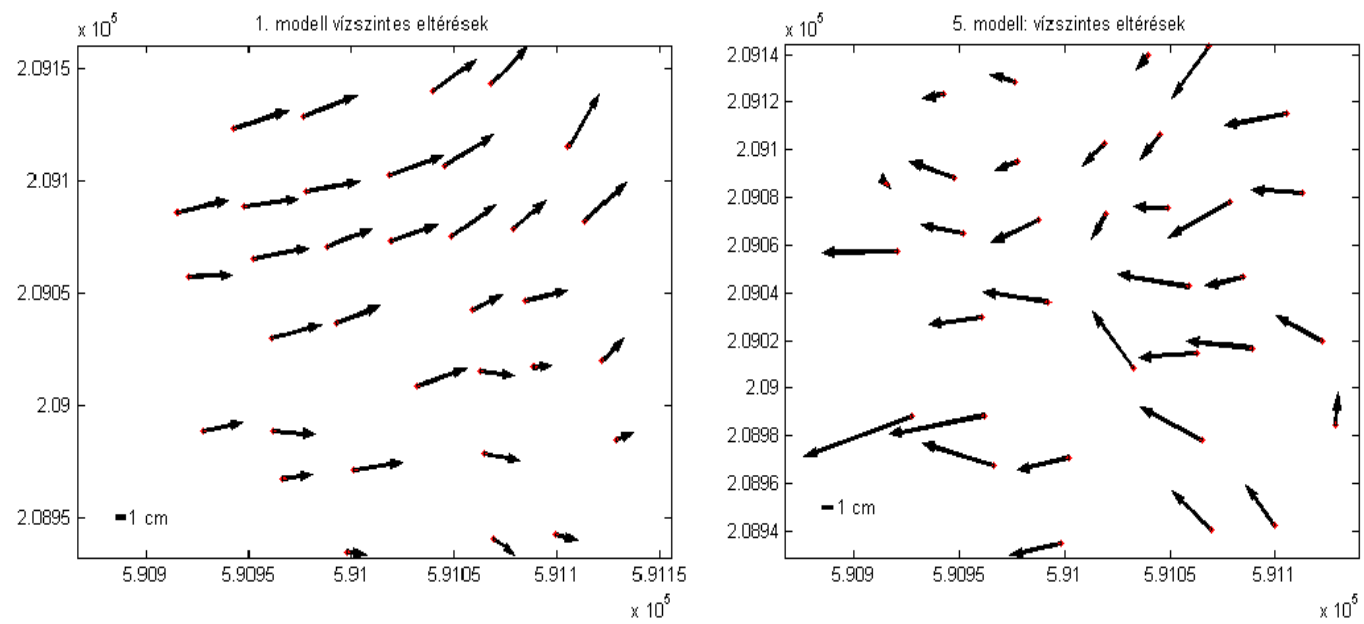

Figure 4: 2D point errors of the test flights for the 1st and 5th cases (examples)

(Balázsik et al., 2016)
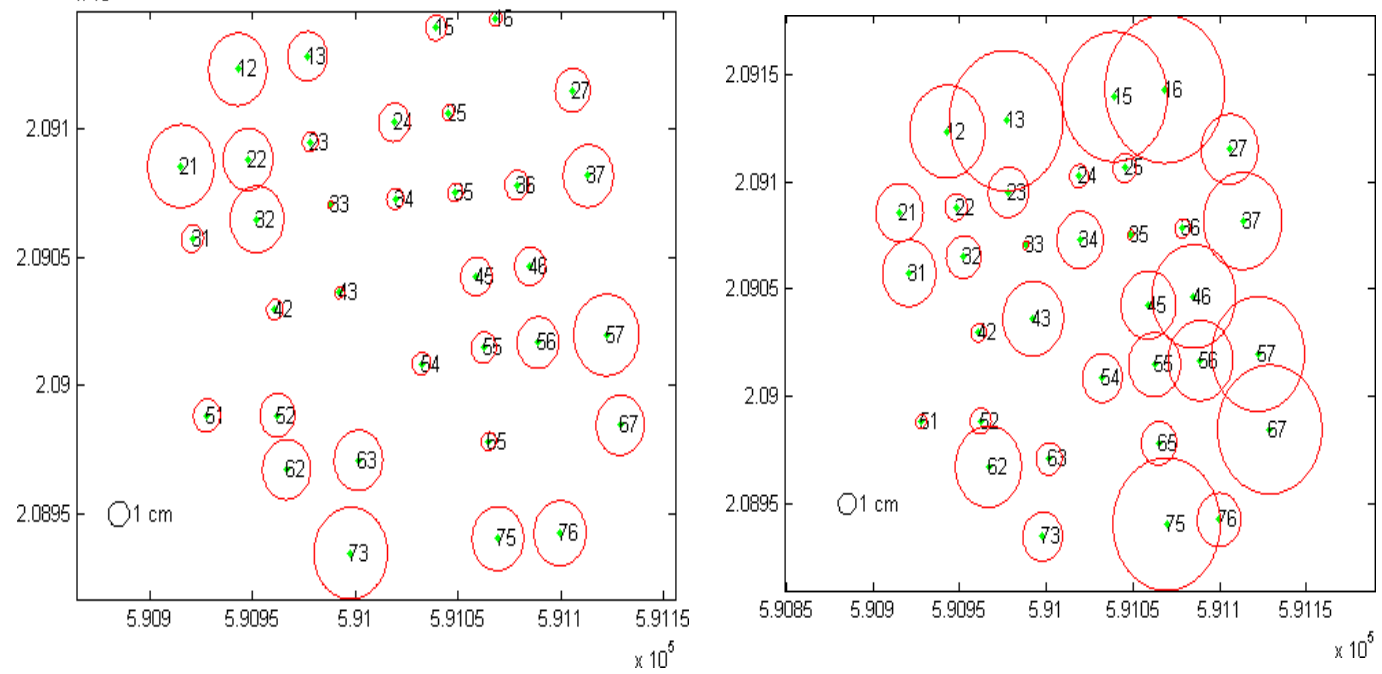

Figure 5: Distribution of horizontal errors of the test flights for the 2 nd and in the 3rd cases.

The examples show only the horizontal error size (Balázsik et al., 2016) 

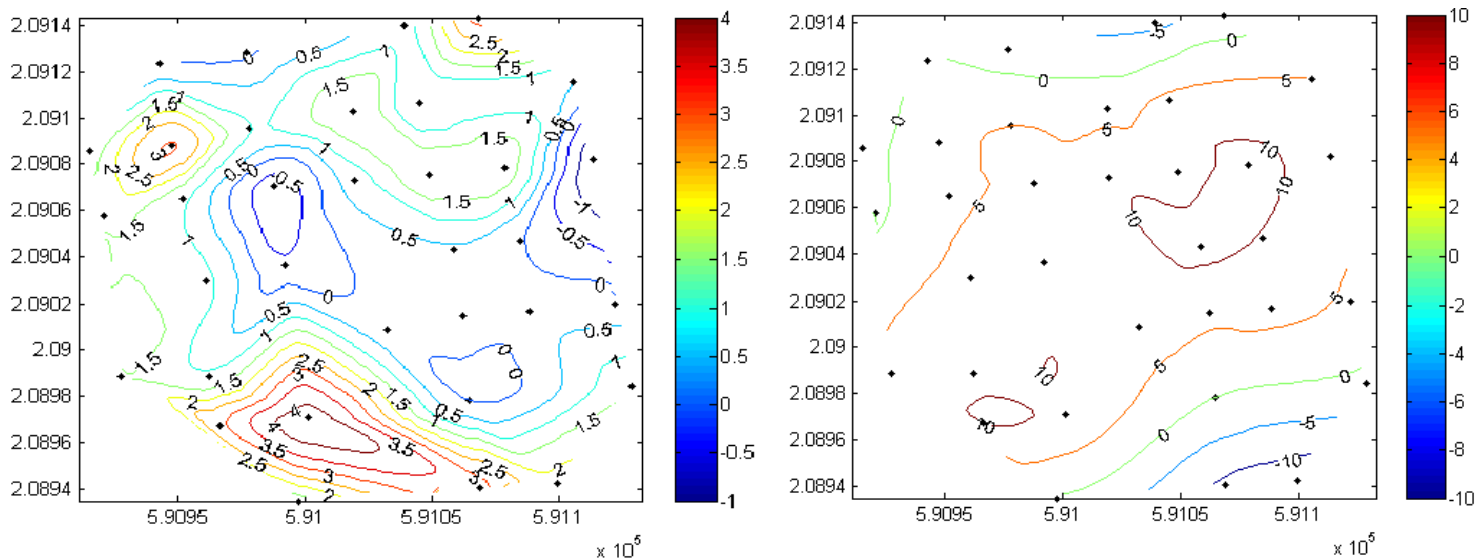

Figure 6: Isolines of height differences for 1st and 5th cases (Balázsik et al., 2016)

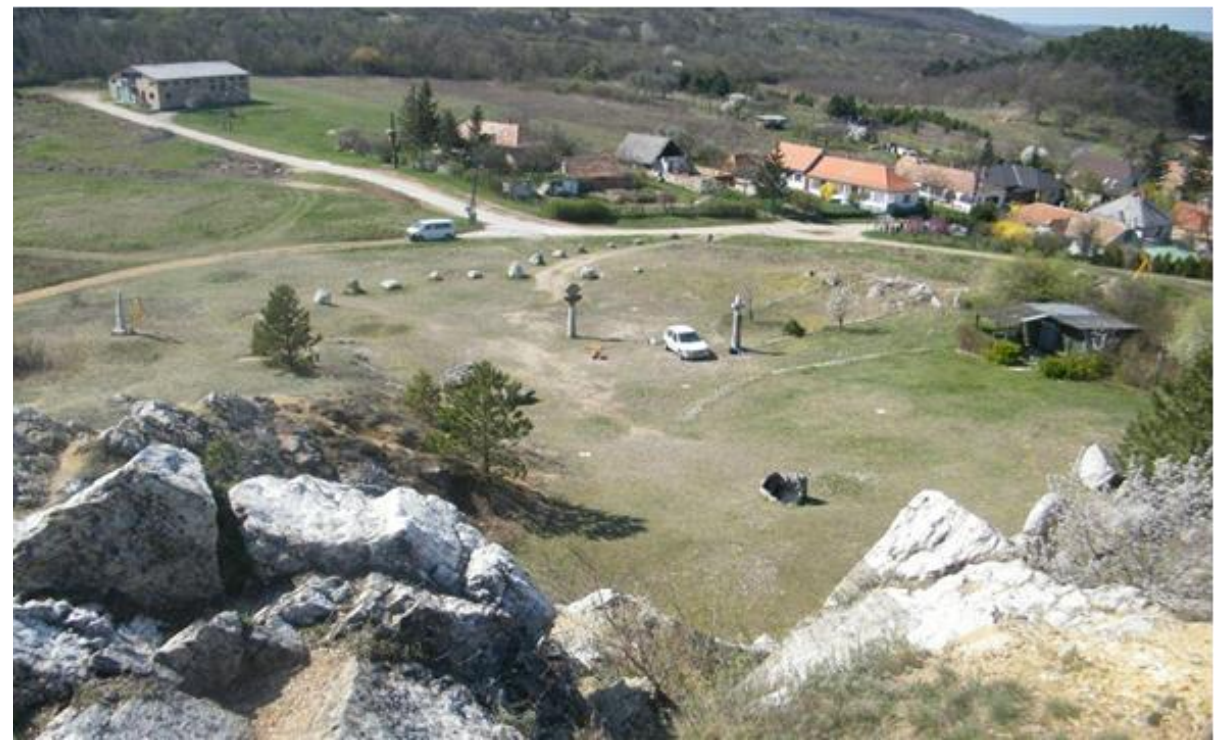

Figure 7: The new test field

\section{Exploring Practical Applications of UAV- Survey}

Nowadays, UAV technology has become part of everyday practice for certain applications. In our previous articles we have provided examples in archeology (Pokrovenszki et al., 2016) and mining (Tóth, 2018). After analysing the test measurements, we present two additional practical examples in which UAV technology has been applied.

\subsection{Creating a Large Scale Engineering Map}

In many engineering applications, the high relative reliability of height data is important. These technologies are typically slow and costly measurements such as levelling or conventional surveying, and usually deliver low resolution map. The purpose of our study is to determine the data accuracy and reliability of data acquisition using $\mathrm{UAV}$, and to answer the question that the short range and high number of overlaps UAV technology may replace the traditional surveying for engineering geodetic tasks. In the example shown on Figure 8, measurements were made on a test field in a horizontal parking lot. From 4 positions (red dots), 6 photogrammetry GCP (yellow dots) and 35 test points were determined conventionally by a total station survey in a local network, which after has been adjusted and inserted into the national reference system of Hungary (Figure 8). Each test point was determined by as many redundant measurements as possible. The results of a purely total station survey were determined by adjustment as an independent network. Network-specific statistics are listed in the Table 3. 


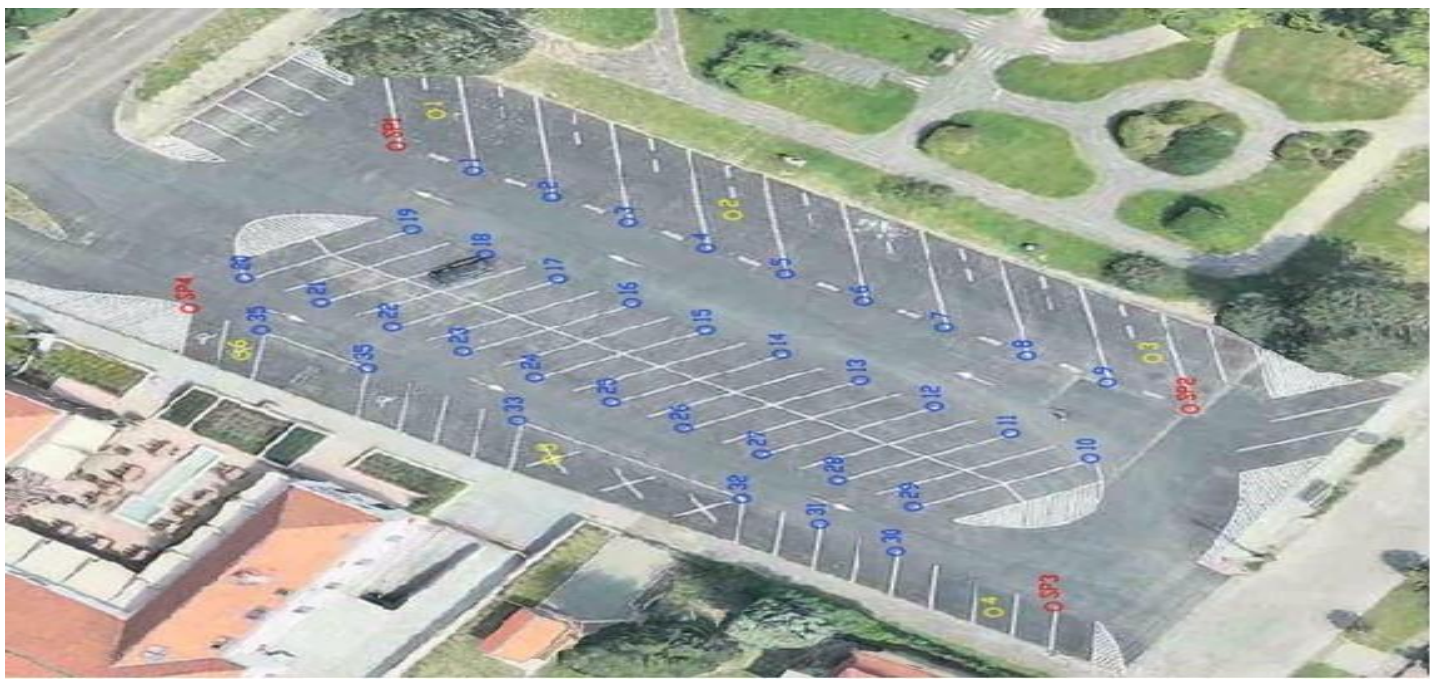

Figure 8: Test field with point marks in a parking lot (Kleszky, 2020)

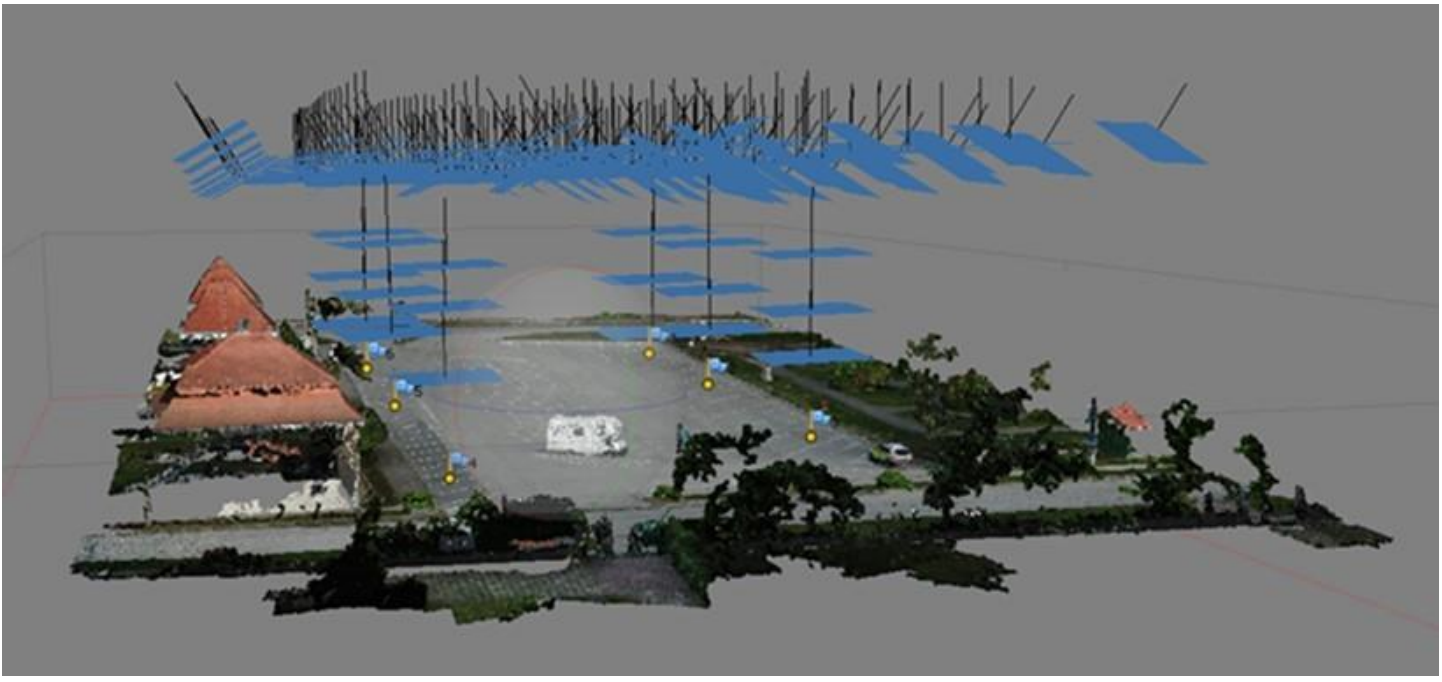

Figure 9: The location and position of images /AGISOFT visualization/ (Kleszky, 2020)

Table 3: Residual errors after the adjustment (Kleszky, 2020)

\begin{tabular}{|c|c|c|c|}
\hline & $\Delta \mathbf{Y}[\mathbf{m m}]$ & $\mathbf{\Delta X}[\mathbf{m m}]$ & $\mathbf{\Delta H}[\mathbf{m m}]$ \\
\hline average & 2,4 & 2,5 & 0,7 \\
\hline maximum & 3,8 & 3,7 & 1,3 \\
\hline
\end{tabular}

Table 4: Deviations on the test points by processing all images (Kleszky, 2020)

\begin{tabular}{|c|c|c|c|}
\hline & $\mathbf{\Delta} \mathbf{Y}[\mathbf{m}]$ & $\mathbf{\Delta}[\mathbf{m}]$ & $\mathbf{\Delta H}[\mathbf{m}]$ \\
\hline average & 0,012 & 0,012 & 0,007 \\
\hline RMS & 0,009 & 0,008 & 0,004 \\
\hline maximum & 0,044 & 0,031 & 0,018 \\
\hline
\end{tabular}

The data in Table 3 show that the network is one order of magnitude more accurate than one would expect from a photogrammetric survey, so it may be suitable for examination. The images were taken with a vertical camera axis, $80 \%$ overlapping in-line and inter-row directions, with a low, $29 \mathrm{~m}$ flight altitude and an estimated $0.9 \mathrm{~cm} /$ pixel geometric resolution. In addition, oblique images (with 60- 
degree camera axis) and lower altitude images were taken with a smaller, approximately $60 \%$ overlapping (Figure 9).

Processing was done with Agisoft Photoscan, using the conventional steps (image alignment, point cloud generation, absolute orientation, surface generation, orthophoto generation). 6 GCPs were added to process. The residual errors of GCP on the georeferenced model were less than $1 \mathrm{~cm}$. In order to compare the results of the traditional and the photogrammetric surveys, the point cloud was displayed in a general-purpose commercial CAD program supplemented with orthophoto mosaic of the area (Figure 10). Test points were manually selected for comparison, thus, of course, the results are also influenced by the quantization of the point cloud. Table 4 summarizes the typical coordinate deviations of the test points measured by the ground survey and determined by UAV technology.

The processing of the photogrammetric survey was repeated using only images with vertical axis (nadir images) and significantly less favourable results were obtained (Table 5). The results obtained with photogrammetric processing are clearly improved by the favourable arrangement of the images. Table 4 shows the reliability achieved with UAV technology, which practically determines its reliable applications. Based on the values obtained, general-purpose surveys can definitely be replaced by this technology. The further advantages of the UAV technology are that the resolution of survey is better, and the time required for the survey is significantly less than conventional (see polar survey) methods. For high-accuracy surveys, additional oblique images can improve the accuracy to achieve the expected quality.

\subsection{Options of UAV Technology in Cadastral Mapping}

Another promising application of UAV-borne photogrammetric surveys is large-scale cadastral mapping surveys.

\subsubsection{Cadastral mapping in Hungary}

In many countries of the world, including Hungary, no digital cadastral maps for the entire country, made by a new survey is available. At those regions of the country where a new survey for digital mapping has not been conducted, older analog maps have been digitized. However, older maps were made in different projection systems, so besides the digital transformation, they had to be transformed into the currently used national projection system. Thus, in addition to errors of drawing and digitizing of the analog maps, the transformation procedure also resulted errors in the data of the digital map. While the reliability of the parcels of the new survey digital cadastral maps is appr. $\pm 9 \mathrm{~cm}$, the reliability of the corner points of the buildings is appr. $\pm 15 \mathrm{~cm}$; nevertheless, in the case of digitized, projected old analog maps these values can be up to meters.

UAV photogrammetry can produce not only high-resolution orthophotos but also 3- dimensional surface models. This can be used to measure the walls of buildings, which were not usually seen on orthophotos produced using traditional aerial photogrammetry, due to the overhang the roof.

Table 5: Deviations on the test points by processing only nadir images (Kleszky, 2020)

\begin{tabular}{|c|c|c|c|}
\hline & $\mathbf{\Delta Y}[\mathbf{m}]$ & $\mathbf{\Delta X}[\mathbf{m}]$ & $\mathbf{\Delta H}[\mathbf{m}]$ \\
\hline average & 0,049 & 0,061 & 0,063 \\
\hline maximum & 0,098 & 0,199 & 0,103 \\
\hline
\end{tabular}

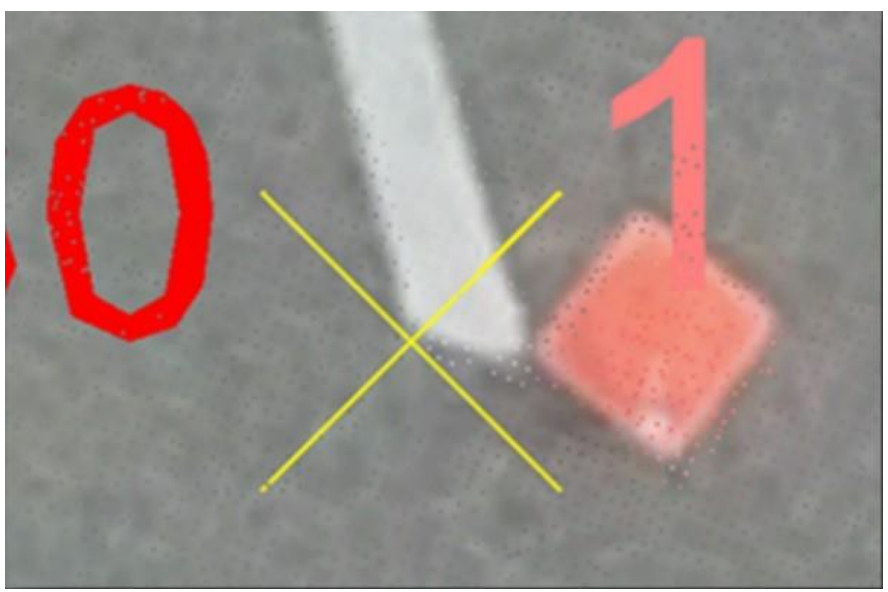

Figure 10: Displaying the point cloud with orthophoto by CAD software (Kleszky, 2020) 


\subsubsection{Cadastral mapping in Uzbekistan}

Multi-purpose geo-information systems are being created in Uzbekistan, base layer of such a system is the land cadaster. The land cadaster is $47 \%$ and the building and construction cadaster is 64\% completed. The cadastral information about land, buildings and constructions, urban areas has been gained by using conventional surveying methods and digital maps created in scales 1:1000 and $1: 2000$. Until now, $80-86 \%$ of cadastral information on buildings and constructions, urban areas have been obtained. The approximate accuracy of the maps for buildings and parcels is $50 \mathrm{~cm}$ (State Committee of the Republic of Uzbekistan, 2019). This accuracy can be ensured by using UAVs for cadastral mapping, and in additional the photogrammetric processing produce a high resolution digital orthophoto in the national reference system, which can be built into GIS database directly.

\subsubsection{Cadastral survey using UAV technology and conventional method}

Our investigations were carried out on a rural block containing 20-30 land parcels. At low flight altitudes of $35 \mathrm{~m}$ were taken images, with overlapping $75 \%$ in-line and $65 \%$ inter-row directions (Figures 11,12). Our aim was to investigate that the resulting orthophoto is suitable to replace the cadastral survey.

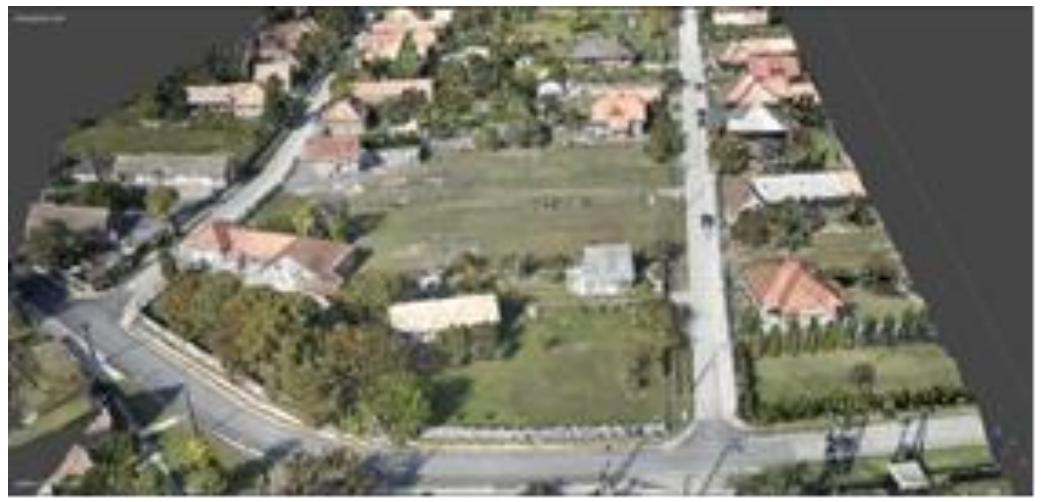

Figure 11: Dense cloud of the area (Schneider, 2020)

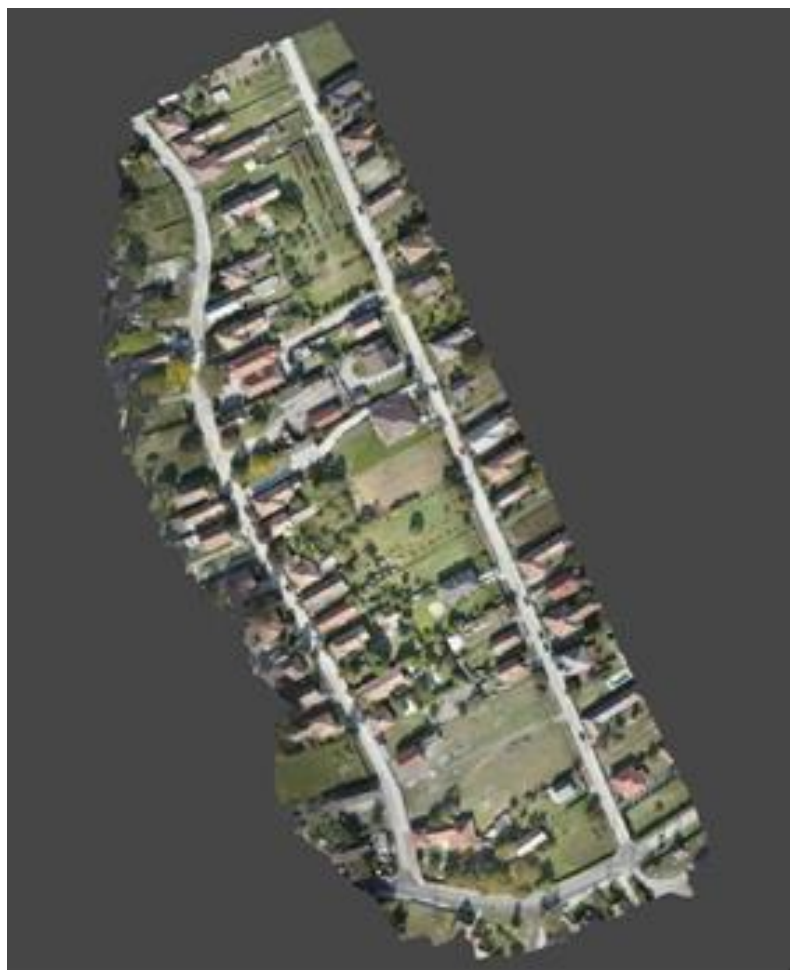

Figure 12: Orthophoto mosaic of the block (Schneider, 2020) 


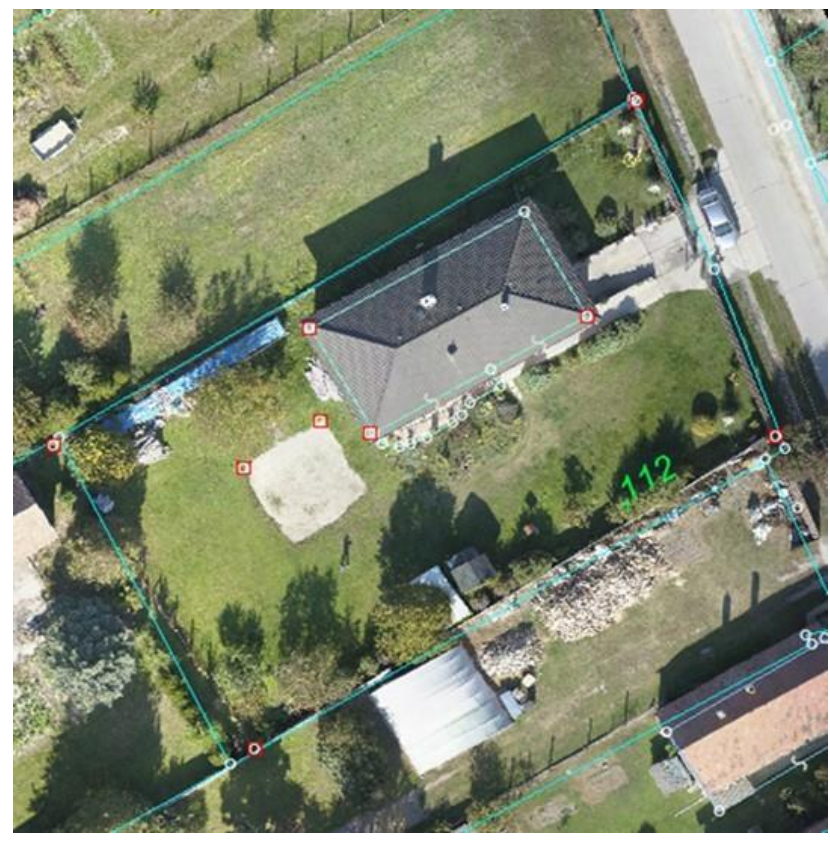

Figure 13: Cadastral map displayed on orthophoto (Schneider, 2020)

Table 6: Differences of coordinates at parcel features points (Schneider, 2020)

\begin{tabular}{|c|c|c|c|c|c|c|}
\hline & \multicolumn{2}{|c|}{ GNSS } & \multicolumn{2}{c|}{ UAV } & & \\
\hline id 112 & $\mathbf{Y}$ & $\mathbf{X}$ & $\mathbf{Y}$ & $\mathbf{X}$ & $\boldsymbol{\Delta} \mathbf{Y}[\mathbf{m}]$ & $\boldsymbol{\Delta} \mathbf{X}[\mathbf{m}]$ \\
\hline $\mathbf{2 3 9}$ & 638738,80 & 196847,22 & 638738,70 & 196847,22 & 0,10 & 0 \\
\hline $\mathbf{2 3 1}$ & 638748,77 & 196822,08 & 638748,67 & 196822,07 & 0,10 & 0,01 \\
\hline $\mathbf{2 3 7}$ & 638711,63 & 196798,56 & 638711,55 & 196798,49 & 0,08 & 0,07 \\
\hline $\mathbf{2 3 8}$ & 638697,28 & 196821,32 & 638697,20 & 196821,35 & 0,08 & $-0,03$ \\
\hline
\end{tabular}

Table 7: Differences of coordinates at parcel features points (Schneider, 2020)

\begin{tabular}{|c|c|c|c|c|c|c|}
\hline & \multicolumn{2}{|c|}{ GNSS } & \multicolumn{2}{c|}{ UAV } & & \\
\hline id 129/1 & $\mathbf{Y}$ & $\mathbf{X}$ & $\mathbf{Y}$ & $\mathbf{X}$ & $\Delta \mathbf{Y}[\mathbf{m}]$ & $\Delta \mathbf{X}[\mathbf{m}]$ \\
\hline $\mathbf{1 3 1}$ & 638603,50 & 196973,68 & 638603,58 & 196973,61 & $-0,08$ & 0,07 \\
\hline $\mathbf{1 3 2}$ & 638604,52 & 196959,52 & 638604,59 & 196959,53 & $-0,07$ & $-0,01$ \\
\hline $\mathbf{1 3 8}$ & 638646,62 & 196981,67 & 638646,70 & 196981,62 & $-0,08$ & 0,05 \\
\hline $\mathbf{1 4 0}$ & 638639,59 & 196993,46 & 638639,62 & 196993,54 & $-0,03$ & $-0,08$ \\
\hline
\end{tabular}

Table 8: Differences of coordinates at parcel features points (Schneider, 2020)

\begin{tabular}{|c|c|c|c|c|c|c|}
\hline & \multicolumn{2}{|c|}{ GNSS } & \multicolumn{2}{c|}{ UAV } & & \\
\hline id 131 & $\mathbf{Y}$ & $\mathbf{X}$ & $\mathbf{Y}$ & $\mathbf{X}$ & $\Delta \mathbf{Y}[\mathbf{m}]$ & $\Delta \mathbf{X}[\mathbf{m}]$ \\
\hline $\mathbf{1 0 2}$ & 638603,29 & 197032,63 & 638603,23 & 197032,61 & 0,06 & 0,02 \\
\hline $\mathbf{1 1 9}$ & 638655,92 & 197060,91 & 638655,84 & 197060,96 & 0,08 & $-0,05$ \\
\hline $\mathbf{1 2 5}$ & 638606,77 & 196992,04 & 638606,69 & 196992,06 & 0,08 & $-0,02$ \\
\hline $\mathbf{1 2 0}$ & 638668,68 & 197026,59 & 638668,75 & 197026,60 & $-0,07$ & $-0,01$ \\
\hline
\end{tabular}


We studied how reliably the elements to be mapped (eg. fence corners) can be identified and how accurate and efficient the technology is. To do this, parcel by parcel we compared the map elements measured by the conventional method and identified from the orthophoto (Figure 13). The Tables 6, 7 and 8 show some typical values. According to the Tables, it can be concluded that the magnitude of the deviations is within the tolerance expected from cadastral surveys. Note that these values are significantly influenced by the reliability of the detail point identification. Due to the nature of some elements, this technology is not, or only partially applicable.

\section{Conclusion}

In this article we have presented accuracy estimates of UAV survey based on image matching photogrammetry. Accuracy estimate has also been presented for two relatively less investigated applications (surveying for cadastral and large scale engineering map). Beyond the known accuracy results, the technology can provide a good basis for cost requirements of the survey. Based on the results of the test measurements and it's low cost, the technology is expected to spread in many areas.

\section{References}

Balázsik, V., Busics, Gy., Engler, P., Farkas, R., Földváry, L., Jancsó, T., Kiss, A., Tóth, Z., Wojtaszek, M. and Verőné, 2016, Establishment of an UAV Calibration Field on Iszka Mountain and the First Results of Accuracy Tests. Remote Sensing Technologies and GIS Online (in Hungarian), Vol. 6(3), 448454.

Honkavaara, E., Saari, H., Kaivosoja, J., Pölönen, I., Hakala, T., Litkey, P., Mäkynen, J. and Pesonen, L., 2013, Processing and Assessment of Spectrometric, Stereoscopic Imagery Collected Using a Lightweight UAV Spectral Camera for Precision Agriculture. Remote Sensing, Vol. 10, 5006-5039.

Kleszky, Á., 2020, Large Scale Mapping Traditionally and with UAV Technology. Thesis Work. Székesfehérvár (in Hungarian).

Pokrovenszki, K., Vágvölgyi, B. and Tóth Z., 2016, Practical Experience with the 3D Photogrammetric Methods used at the Excavation of Csókakő Castle. Magyar Régészet, 20-27.

Schneider, T., 2020, Application of UAV-borne Data Acquisition for Land Registry, Thesis Work. Székesfehérvár. (in Hungarian).
State Committee of the Republic of Uzbekistan on Land Resources, Geodesy, Cartography and State Cadastre, 2019, National report on the state of land resources of the Republic of Uzbekistan, Tashkent, 64.

Hamid, N. F. A. and Ahmad A., 2014, Calibration of High Resolution Digital Camera Based on Different Photogrammetric Methods, 8th International Symposium of the Digital Earth (ISDE8), OP Conf. Series: Earth and Environmental Science, Vol. 18(1), 1-6, DOI: 10.1088/1755-1315/18/1/012030.

Tóth, Z., 2018, Remote-Sensing-Methods-forOpen-Pit-Mine-Surveying. In: Orosz G. (ed.) AIS 2018 - 13th International Symposium on Applied Informatics and Related Areas, Székesfehérvár, 4.

Tommaselli, A. M. G., Berveglieri, A., Oliveira, R. A., Nagai, L. Y. and Honkavaara E., 2016, Orientation and Calibration Requirements for Hyperpectral Imaging Using Uavs: A Case Study. The International Archives of the Photogrammetry, Remote Sensing and Spatial Information Sciences, Vol. XL-3/W4, 109-115.

Tommaselli, A. M. G., Marcato, Jr. J., Moraes, M. V. A., Silva, S. L. A. and Artero, A. O., 2014. Calibration of Panoramic Cameras with Coded Targets and a3d Calibration Field. The International Archives of the Photogrammetry, Remote Sensing and Spatial Information Sciences, Vol. XL-3/W1, 137-142, https://doi.org/10.5194/isprsarchives-XL-3-W1137-2014, 2014. 